\title{
MODERNIDAD, COVID-19, Y COLONIALIDAD EN EL PERÚ.
}

NOTAS INTRODUCTORIAS*1

Modernity, Covid-19, and coloniality in Peru introductory notes

NAVARRETE, Julio Mejía²

Resumen: La actual crisis de la modernidad global se encuentra teñida, en gran parte, por el malestar que genera el Covid-19, como amenazas severas que trazan un horizonte gris, portador de desconfianza, incertidumbre y miedo de un futuro que puede replicar las fuerzas nebulosas de la colonialidad en todas partes del planeta. El estudio no espera ser acabado, apenas traza algunas ideas centrales de la vida social, lo importante es destacar algunos elementos cardinales que permitan comprender los tiempos críticos presentes. Interesa recatar para su análisis las transformaciones del patrón moderno global y los posibles impactos que generan en el Perú. Experiencias de la vida social afectada por la pandemia grafican que solo tiene posibilidad el desarrollo de una lógica que vaya más allá del mercado. El miedo a la enfermedad tiene que vencer al individualismo del mercado, hay necesidad de recuperar la energía colectiva que produce el afecto, la confianza de la compañía duradera con los otros y la fortaleza de la comunidad. Punto inicial que posibilite situar en el centro de la sociedad la vida digna de las personas. Garantizando que los derechos fundamentales son la condición propia de ser humanos.

Palabras-clave: Covid-19. Colonialidad. Modernidad.

Abstract: The current crisis of global modernity is colored, to a large extent, by the discomfort generated by Covid-19, as severe threats that draw a gray horizon, bearer of mistrust, uncertainty and fear of a future that can replicate the nebulous forces of coloniality in all parts of the planet. The study does not wait to be finished, it only traces some central ideas of social life, the important thing is to highlight some cardinal elements that allow us to understand the present critical times. It is interesting to recall for analysis the transformations of the modern global pattern and the possible impacts that they generate in Peru. Experiences of social life affected by the pandemic show that only the development of a logic that goes beyond the market has the possibility. The fear of the disease has to overcome the individualism of the market, there is a need to recover the collective energy that produces affection, the trust of the lasting company with others and the strength of the community. Starting point that makes it possible to place the dignified life of people at the center of society. Guaranteeing that fundamental rights are the proper condition of being human.

Keywords: Covid-19. Coloniality. Modernity.

\footnotetext{
"Versión revisada de la ponencia en la Mesa Redonda Virtual "Modernidad, Covid-19 y colonialidad", organizada por la Facultad de Ciencias Sociales de la Universidad Nacional Mayor de San Marcos, Lima, 22 de mayo de 2020.

${ }^{1}$ Recebido em: 27 Jun. 2020 | 30 Set. 2020.

2 Docente investigador. Doctor en Sociología. Ejerce la docencia en la Universidad Nacional Mayor de San Marcos. Actualmente es Decano de la Facultad de Ciencias Sociales de la UNMSM. https://orcid.org/0000 0002-4170-5643
} 


\section{Introducción}

La pandemia del coronavirus expresa las tendencias generales del patrón moderno global y pareciera que la crisis abierta exponencia el modelado del curso de la sociedad, cuyas repercusiones continuaran cuando se diluya la enfermedad, marcando su lado más sombrío, de la colonialidad. Indudablemente, el mundo proseguirá desplegándose, pero lo hará según el sentido de la historia que interrelaciona modernidad y colonialidad, a no ser que haya un giro profundo en la organización de la existencia social. En ese sentido, la pandemia es parte del proceso que Aníbal Quijano denomina “crisis raigal de la colonialidad global del poder" (2014, p. 27), después de más de 500 años, desde la conquista de América, probablemente el sistema moderno estaría llegando a sus limites, al acrecentar la destrucción de la naturaleza y agudizar una concentración de la riqueza y desigualdades que amenazan las formas de vida en la Tierra.

La actual crisis de la modernidad global se encuentra teñida, en gran parte, por el malestar que genera el Covid-19, como amenazas severas que trazan un horizonte gris, portador de desconfianza, incertidumbre y miedo de un futuro que puede replicar las fuerzas nebulosas de la colonialidad en todas partes del planeta.

El estudio no espera ser acabado, apenas traza algunas ideas centrales de la vida social, lo importante es destacar algunos elementos cardinales que permitan comprender los tiempos críticos presentes. Interesa recatar para su análisis las transformaciones del patrón moderno global y los posibles impactos que generan en el Perú.

\section{Covid-19: intensificación de la precarización, pobreza y desigualdad social}

En el Mundo la desigualdad social es la principal forma como se extiende la pandemia del Covid-19, los humanos pertenecemos a sociedades inestables que trazan grandes diferencias, que siempre aquejan más a los pobres y dibujan el movimiento y ritmo del desarrollo de la enfermedad.

La particularidad de la crisis del Covid-19 agudiza la precariedad, pobreza y desigualdad en las poblaciones de la Tierra. Antes de la pandemia los más ricos existían en un mundo donde la pobreza parecía estar controlada e incluso disminuía, es el caso de 
Perú, Chile y los propios países desarrollados. En cambio ahora, los grandes ricos se vuelven más y lo hacen en un contexto global donde se incrementa desorbitantemente la pobreza. La desigualdad moderna se desarrolla en forma abierta y cínica.

Una de las consecuencias más importantes de la pandemia es que la diferencia entre países desarrollados y los periféricos tiende ha desaparecer en forma definitiva. Aquella divergencia entre las zonas del ser, donde predominaba los derechos y regulación, y las zonas del no-ser, donde tenían hegemonía la violencia y dominación (Fanon 2001). El Covid-19 afecta a los países en forma similar, acompañando a la geopolítica mundial, todos incluyen mayorías pobres del sur global y élites del norte global.

Sin embargo, la epidemia sigue las tendencias de la desigualdad global. La vida saludable, las tasas de mortalidad y el acceso a los servicios de salud han sido marcadamente diferentes en periodos anteriores a la pandemia entre las capas medias y las élites con los sectores más pobres, en estos momentos de crisis la vulnerabilidad social se encuentra gravemente afectada por el desarrollo de la enfermedad. En la ciudad de New York la mortalidad de la pandemia afectó más a las poblaciones de hispanos en un 34\% y de negros en un 28\% (La Vanguardia, 2020). En Río de Janeiro la letalidad es de 13 veces mayor para las favelas en comparación con los barrios más ricos (Zibechi, 2020). En la ciudad de Barcelona la ocurrencia de la mortalidad es un 26\% menor en los barrios de mayores ingresos que en los barrios con menores rentas (Salas, 2020). En general, las condiciones sociales en la vida de las personas es fundamental, aunque no el único factor, en la expansión del Covid-19.

Ello tiene que ver con el aumento creciente de la riqueza en las élites y la persistente ampliación de la pobreza para las mayorías. Los Estados Unidos en medio de la cuarentena parcial, los más de 600 multimillonarios aumentarón sus fortunas en 434 mil millones de dólares, entre marzo y mayo, mientras que 38.6 millones de personas perdieron sus empleos (Brooks, 2020). En ese marco de gran desigualdad, el desempleo recorre la paralización de la vida económica, para el mundo se estima la pérdida de 230 millones de empleos a tiempo completo de 40 horas, en los países con mayores ingresos la cifra es de 36 millones, mientras que para los países con menores ingresos se calcula en 14 millones (OIT, 2020a). Los países pobres, aquellos con menores ingresos, tienen las tasas más altas debido al desarrollo de la informalidad, cuyos estimados llegan a 197 millones de personas muy afectados por la reciente pandemia (OIT, 2020b). En ese 
sentido, la irradiación de la pobreza en el planeta se sitúa entre 40 y 60 millones de personas (Banco Mundial, 2020). Para América Latina la pobreza podría alcanzar los 214.7 millones y la pobreza extrema llegaría a afectar a 83.4 millones de habitantes (CEPAL, 2020). La propagación del Covid-19 en un contexto de modernidad neoliberal expone la brutal concentración de riquezas y la gigantesca desigualdad social.

Se trata de un mundo desbocado, de precariedad, flexibilidad y pobreza para la mayor parte de la población. Destrucción masiva de trabajo, muy difícil de recuperar en el futuro inmediato dadas las condiciones de la revolución tecnológica e inteligencia artificial que redefinen las estructuras productivas. El sistema-moderno no necesita de trabajo asalariado en sus niveles más dinámicos, es probable que se ensanche más el desempleo estructural, el precariado, la informalidad y el trabajo forzado (Standing, 2016).

A la par, se desarrolla una cultura que sustrae el rostro del pobre, para despojarlo de todos los elementos de su identidad, excepto el ser marginados y excluidos, expropiando sus facultades para convertirlos en seres indignos, humillados y privados de sus derechos. Nos enfrentamos a una sociedad que privilegia a las élites clasificándolas como superiores y, de otro lado, clasifica a sectores importantes de la población como seres inferiores y, de esa forma, poder revertir su humanidad (Mejía, 2016).

\section{Destrucción de la naturaleza}

El otro aspecto de la precarización e inferiorización de la población, es la destrucción de la naturaleza por la el patrón moderno que puede poner en peligro esta forma de vida existente sobre la Tierra, influyendo de forma determinante en la aparición del Covid-19.

El equilibrio autopoiético del planeta Tierra formado por la interrelación de lo físico, químico, biológico y lo humano se ha roto desde hace 500 años por expansión desenfrenada de la modernidad (Lavelock, 2007), afectando la diversidad de la organización de la vida, que tiene en lo humano su dimensión dominante. La destrucción de la naturaleza lleva varios siglos de explotación progresiva, hoy es más grave la 
supervivencia de las especies, simplemente porque la modernidad global exponenció su mortanda, contamos con los medios químicos, herramientas mecánicas, tecnologías sofisticadas e inteligencia artificial para exterminar a los seres vivos, llevando a niveles catastróficos la brecha entre la acumulación ilimitada del capital y los recursos limitados de la naturaleza. Actualmente está en desarrollo la sexta extinción a gran escala de la vida en la Tierra, la tasa de mortandad de seres vivos es 100 veces más alta que la propia tasa natural (Ceballos et al., 2015). De los 8 millones de especies animales y vegetales existentes, 1 de cada 8 están seriamente amenazados por la modernidad. Se estima que las próximos décadas muchas de las especies puedan desaparecer del mundo (ipbes, 2019). Pareciera que habríamos ingresado irremediablemente a un momento histórico donde la modernidad puede afectar gravemente la propia existencia de la humanidad y toda manifestaciones de vida en el planeta Tierra.

Antes de la pandemia, en el 2019 se desataron gigantescos incendios en la Amazonía sudamericana, generalmente provocados por intereses de ganaderos para erradicar los árboles y las personas. Siendo los incendios más graves en Australia que involucró alrededor de 10 millones de Has., arrasando territorios y biodiversidad, produciendo una híper criminalidad de mil millones de animales muertos (Elcacho, 2020), cuyas repercusiones recién comienzan a experimentarse para la humanidad.

En ese contexto, la tesis más convincente de la causa del Covid-19, de amplio acuerdo entre los investigadores internacionales, es que el virus ha saltado de un animal a otro y de ahí a los humanos. Los animales tienen en sus organismos virus desconocidos, que por su evolución de miles de años desarrollaron sus propios anticuerpos, pero por la destrucción de los hábitats naturales llevada por expansión de la modernidad, la destrucción de ecosistemas, del crecimiento constante de las ciudades, la invasión de espacios naturales y el tráfico de animales, condiciones que hacen que las especies se vuelven muy vulnerables y miles de virus comienzan afectar a los humanos.

Frente a la grave crisis de salud pública directamente vinculada a la pérdida de la biodiversidad del planeta y la destrucción de la naturaleza que empuja a la aparición de enfermedades en el ser humano, los factores son variados, auque resaltan por su influencia la propagación de los zoonóticos (Suarez et al., 2020, p. 6). Precisamente, la Organización Mundial de la Salud estima que el 61\% de los patógenos humanos son zoonóticos y representan el $75 \%$ de todas las enfermedades emergentes durante la última 
década (OMS). Es probable que esta forma de virus del Covid-19 haya surgido al Sur de la China y de ahí se expandió por todos los rincones del mundo (Ramonet, 2020).

\section{Patrón moderno digital}

El anuncio de la "era de la información" especificado por su mayor exponente Manuel Castells (1997), producto de los cambios impulsados por la revolución en las tecnologías de la información y la comunicación, apoyados en la asociación de la microelectrónica, las telecomunicaciones y la ingeniería genética, probablemente con la pandemia y sus medidas de encierro de las poblaciones en el mundo hayan acelerado en forma decidida su desarrollo. Acrecentando los procesos de la modernidad en el siglo XXI, que integra en una unidad colonialidad y mundo digital, que trasfigura las manera de vivir y la comunicación entre los seres humanos.

El encierro, la cuarentea y la inmovilidad sujetan a hombres y mujeres en sus hogares, estableciendo que la virtualidad a nivel mundial, involucre al conjunto de generaciones de niños, adultos y mayores, y abarque todos los aspectos dela vida social, educación, economía, sociedad, política, cultura, etc., prácticamente el uso de internet se ha duplicado, creciendo en un $80 \%$ (Ramonet 2020) y se ha convertido en la forma natural de comunicación y socialización entre los humanos.

Todos los sueños de un mundo plano, de igualdad de redes globales, pareciera que han terminado abruptamente y más bien hemos ingresado en una sociedad dominada por oligopolios de unas pocas empresas gigantescas de comunicación digital, como Google, Facebook, Twitter, Apple y Amazon, interesadas en convertir todas las actividades de las redes en fuente de datos y en el origen principal del beneficio económico.

Con la pandemia global estamos despuntando un espacio digital que habitar. Sin embargo, la crisis producida por el Covid-19 estan trastocando las nuevas tecnologías en herramientas de vigilancia y control individual. Especialmente en los países que rapidamente se han impuesto a la enfermedad como China, Corea del Sur e Israel, donde fue desarrollado por los servicios de inteligencia, ahora convertidos en mecanismos para monotorizar a las personas, poniendo en cuestión la vida privada y las libertades a cambio 
de la seguridad. Los teléfonos celulares, los programas informáticos y la inteligencia artificial desarrollaron camaras de reconocimiento facial, medición de la temperatura, permitiendo obtener miles de datos biométricos que permiten seguir a los individuos minuciosamente (Harari, 2020).

La crisis es un campo político global que posibilita desarrollar en las gentes técnicas verticales de dominio de la vida cotidiana y del control individual. La particularidd del momento actual, que frente al miedo de la pandemia es el propio individuo quien solicita la autosupervición y autocontrol, no es el viejo panoptico que suponía la inspección y seguimiento de manera externa y centralizada por las instituciones del Estado (Bauman, 2007, Cap. I). Podemos estar cursando el camino a formas tecnoautoritarias verticales de dominio de cada persona, no es una casualidad que lo hayan desarrollado con éxito gobiernos no democráticos o impulsados por políticas autoritarias, que cuestionan los derechos y libertades individuales.

Por otro lado, el patrón moderno digital viene alentando principalmente en sus élites ultraconservadoras un proyecto global de "barbarie cultural", que tienen como aspecto central la relegitimación del racismo, especialmente desde la elección del presidente Donald Trump, el 20 de enero de 2017, se vuelve a incorporar en el Estado el discurso racial y la epistemología violenta que ponen en tela de juicio la humanidad de sectores importantes de la población y cuestiona la existencia del cambio climático. Proyecto que hace uso intensivo de medios y redes informáticos con el fin de de crear personas poco educadas, mal informadas y enteramente sumisas (Castells, 2019).

La crisis de la pandemia ha potenciado el uso de robots informáticos que ocupan las redes globales, trasmitiendo y modificando los contenidos, se estima entre un millón o dos millones de mensajes antidemocráticos y agresivos (Castells, 2020). En esa situación, es posible que la elección de Trump, Bolsonaro en el Brasil y la salida de Inglaterra de la unión Europea fueron condicionados por la utilización de los robts informáticos. Nos enfrentamos a la expansión de mensajes ideológicos que se difunden en las redes globales, fundamentalmente generados por fuerzas conservadoras que utilizan la crisis para reavivar los discursos violentos contra sectores de la humanidad y la naturaleza. 
En general, la pandemia precipita el desarrollo de una "modernidad sin des/colonialidad" (Quijano, 2014), en otra palabras asistimos a la experiencia de una "modernidad sin modernismo" (Bauman, 213). Se vienen expandiendo activamente la modernidad digital y el crecimiento de sus formas de colonialidad, de la desigualdad social, la destrucción de la naturaleza, los oligopolios, las formas de autocontrol y la imposición de un proyecto de "barbarie cultural". Las promesas originarias de la modernidad de una sociedad justa y de libertad individual se alejan o se buscan anularlas, en un mundo donde tendrían posibilidades de desarrollo lo barbaro y la realización de las distopías.

\section{Impacto del Covid-19 en el Perú}

Las repercusiones de la crisis de la pandemia en el Perú se analiza en los siguientes puntos esenciales: la situación socioeconómica, el carácter de las políticas publicas y las tendencias generadas en la vida cotidiana de las personas.

\section{Covid-19 y situación socioeconómica}

El Perú transita por un proceso de hondas modificaciones desde las últimas décadas del siglo pasado. Los cambios son productos principalmente de la hegemonía del neoliberalismo. Partimos de la idea que la pandemia en el Perú es muy grave sin llegar a ser los extremos trágicos de EE UU, Brasil, México Italia, Reino Unido (Cuadro 1). Sin embargo, pareciera que la situación socioeconómica puede llegar a ser más funesta.

\section{Cuadro 1}

\section{Contagiados, fallecidos y tasa de letalidad}

del Covid-19 en algunos países 


\begin{tabular}{lccc}
\hline \multicolumn{1}{c}{ Países } & Contagiados & Fallecidos & Tasa de letalidad \\
\hline Mundo & $7^{\prime} 038,942$ & 403,267 & 5.7 \\
EE. UU. & $1^{\prime} 94,2363$ & 110,514 & 5.6 \\
Italia & 234,998 & 33,899 & 14.4 \\
Reino Unido & 287,621 & 40,625 & 14.1 \\
Brasil & 691,758 & 36,455 & 5.3 \\
México & 117,103 & 13,699 & 11.7 \\
Perú & 196,515 & 5,465 & 2.8 \\
\hline
\end{tabular}

FUENTE: Hopkins, J. (2020)

En momentos del Covid-19 la situación socioeconómica en el Perú es muy adversa, tendrá un impacto directo sobre el incremento de la precaridad del empleo, la informalidad y el nivel de pobreza. Muchas personas que estaban ingresando y afiazándose en la clase media emergente podrían volver a la condición de pobreza.

La economía peruana en el 2020 por efectos de la paralización provocada por la pandemia del Covid-19, es probable que sufra una contracción cercana entre $20 \%$ y 25\%, que incluso llegaría a una reducción del 35\% y 40\% en el PBI, como lo fuera en la Guerra del Pacífico (Seminario, 2020). El modelo de desarrollo actual que tiene mayor presencia desde la década de los noventa del siglo pasado es el neoliberalismo, el crecimiento económico lo hace dependiente fundamentalmente del accionar mercado, aunque en los últimos años rearticuló tímidamente la presencia de la actuación estatal en la distribución de recursos para los sectores más vulnerables y en el aumento de las capacidades productivas. Modelo neoliberal vinculado estrechamente a la expansión de la China por medio del "extractivismo informacional" (Calderón y Castells, 2019), debido especialmente a la exportación de productos mineros, que comprenden la destrucción de la territoritorialidad, con la ecológica existente y el aumento de la desigualdad social.

De esa manera, la crisis abierta por la enfermedad amplió crecientemente el desempleo, solo en Lima lo elevó a 1'216,600 entre los meses de febrero y abril (INEI, 2020). La pobreza se extiende constantemente, pasaría del 20.2\% estimado para el 2019 al 25\% - 26\% según las informaciones de la CEPAL (2020). La informalidad haría que un 
$50 \%$ de personas esten en posibilidades de abandonar el encierro en el hogar por la necesidad de buscar algún trabajo (Montoya, 2020). Los sectores poblaciones vulnerables culculadas en $34.2 \%$ para 2018 , al rededor de 10.8 millones de personas, correrían el riesgo de volver a la situación de carencias sociales en el presente, los pobres se calculaban en $29.5 \%$ podrían llegar a duplicarse en el país por la paralización económica del 2020 (Peñaranda, 2019).

El resultado de las díficiles condiciones sociales en el Perú originan el aumento del desempleo, precariado, informalidad y trabajo forzoso. Riesgo social que puede hacer que el deterioro sea mayor en la salud y en la extensión de la pandemia. La población se desliza a una situación muy crítica, con menos derechos, más dominación y la posibilidad de bordear en el trato deshumanizado.

Las políticas públicas frente al Covid-19

En el Perú las políticas públicas frente al Covid-19 expresarían los agudos resultados de la globalización, en particular en lo referente a la separación entre el poder global y la política local. El poder es más global, sigue la distribución mundial del capital, mientras que a la política local le compete principalmente las actuaciones gubernamentales en relación a las personas. Cuando el Estado busca orientarse a lo global su accionar frente a la población local se torna secundario. La falta de capacidad para controlar los poderes mundiales, se transforma en un principio de incertidumbre y le resta importancia a las instituciones políticas que tiene menos posibilidades de responder a los problemas cotidianos de las gentes (Castells 1997, Cap. 5, Vol. 2). Precisamente, la mayor expresión de las políticas locales en el Perú es el debilitamiento del sistema de salud durante los últimos 40 años, su expresión mayor en el impacto de la pandemia son los 1,061 medicos contagiados y 26 de ellos muertos (EFE, 2020).

En ese cuadro, las políticas publicas frente al Covid-19 se encuentran sometidas a los límites sistémicos globales del poder. Las políticas públicas fundamentalmente se han restringido a las actuaciones de las tranferencias de recursos económicos a los diversos sectores sociales, según el modelo de la mayoría de países como Alemania y Estados Unidos. Por supuesto que las transferencias de recursos evidencian las radicales 
desiguadades de cada nación, en el Perú se distribuyeron 60 mil millones de soles, en dos paquetes, a los grandes Bancos y mayores empresas. A las pequeñas y micro empresas les correspondió apenas el 2\%. El bono universal destinado a las personas de escasos ingresos se estima en 5 mil milloes de soles. En general, se crea una situación que beneficia 12 veces a favor de los 4 Bancos mayores del país (Francke, 2020). El Estado al querer dirigirse a la globalización del poder, se ve en la necesidad de sacrificar aún más los intereses de la población.

En tiempos de crisis impulsado por la pandemia, la mayor actuación de la política local del gobierno peruano recae en el mantenimiento del orden. Las otras funciones del Estado se reducen o la comparten con otros poderes. La política local del orden interno frente al Covid-19 se orienta esencialmente a la reclusión de la población en sus hogares. La política local del orden interno intenta combinar el confinamiento espacial de la vivienda con el social de la familia y busca llevar el enclaustramiento obligatorio que impediera la salidad de sus habitantes.

En esas condiciones, probablemente la política del encierro se encuentra en dificultades serias, no puede impedir que las personas abandonen la inmovilidad, emerge un desborde popular del orden que afecta a sus propios cuidadores, la policía ha sufrido más de 4 mil contagiados y 82 muertos, lo que revela la fragilidad de las intervenciones del confinamiento (Gestión, 2020). Asimismo, la política de inmovilidad expresa delicadas fallas, las disposiciones del 22 de mayo último propiciarían que una tercera parte creciente de la población salga a trabajar, vaya al mercado, al banco, a la peluquería, en otros términos carece de sustento adecuado para poder llegar a ser una cuarentena. La propia ministra de la Producción, declaró que más de seis millones de peruanos con negocio podrán "hacer sus oficios" fuera de los hogares.

La situación del encierro es paralelo y complementario a la pobreza y a sus formas de criminalización (Bauman 2006, p. 117). En particular, la cuarentena tiene serios limites para controlar a los habitantes en el país. En especial, porque se trata de una población caracterizada por la informalidad en un 70\%, vive al día, sea en pequeños negocios o de actidades callejeras, tiene la urgencia imperiosa de salir fuera de sus viviendas, rompiendo el circulo del confinamiento obligatorio. Además es importante anotar, que la población procede de la civilización andina, desestima las davidas o regalos de dinero, posee una alta valoración del trabajo (Adams y Valdivia, 1991). 
En situación equivalente, aunque más extrema, se encuentran los 860,000 migrantes venezolanos, que para el año de 2020 el 93\% se encontraba como informales, con un $83 \%$ sin ingresos por la crisis del Covid-19, sin seguro de salud y en peligro de desalojo de las viviendas en un 52\% (Freier y Brauckmeyer, 2020). Se trata de una población altamente vulnerable que retrata en toda su dimensión el apuro de salir para trabajar. La acción limitada del encierro frente al temor de la pandemia, pone en jaque la propia política local que principalmente gira en torno del orden interno.

De igual forma, se observa en la immigración de regreso al interior del país, la vuelta a las provincias y áreas rurales se ha convertido en un problema serio que afecta la inmovilidad hogareña, se estima en alrededor de 167 mil personas abandonan Lima por la búsqueda de compañía, solidaridad y alimentos (Zibechi, 2020). La inmigración de regreso resquebraja la politica local de confinamiento obligatorio por la pobreza de sus habitantes, aunque puede llevar a otros encierros en sus los lugares de origen y destino.

Por otra parte, la criminalización de la pobreza conlleva la clausura obligatoria extrema. En últimos años el país en ha crecido constantemente la población de las cárceles hasta llegar al 97,479, en su mayoría internos que cometieron actos delictivos propio de los pobres, el 73,2\% son delitos asociados contra el patrimonio, contra la libertad sexual y las drogas. La mayoría de cárceles se encuetran en condiciones de grave hacinamiento y peligro de transformarse en espacios infecciosos, convirténdolos en instancias de gran vulenerabilidad frente al Covid-19. La respuesta social en las cárcels es la explosión de motines y protestas que directamente cuestionan la autoridad y la politica local del encierro en los diversos penales del país, Piura, Chiclayo, Trujillo, Huancayo, Ica, Chiclayo y Lima (Perez Guadalupe, 2020).

En el Perú el encerramiento muestra la vinculación estrecha entre pobreza y su criminalización por el intercambio de la población entre ambos ámbitos y, sobre todo, porque expresan las limitaciones del mercado y de las políticas frente al Covid-19, que obligan a sus poblaciones a no resistir el encierro obligatorio. En ese sentido, pareciera que el miedo no solo tiene que ver con las amenazas de la enfermedad, sino principalmente por la falta de nitidez de las políticas públicas, lo único certero sería la incertidumbre prolongada, esencialmente por el desconocimiento sobre la propia enfermedad y la impotencia para influir en su futuro (Bauman y Dessal 2014, p. 21). 
La política pública del país frente al Covid-19 por un lado, ha seguido la trayectoria de la globalización del capital y, por otra, ha tenido como función central las actuaciones locales de encierro, que han sido desbordadas por la población más pobre, poniendo en crisis las intervenciones del orden interno.

Vida cotidiana en el encierro

El encierro de estas semanas debido a la crisis que desato la pandemia, alentó más a la población a situarse frente a la disyuntiva de seguridad vs. Libertad, que tanto preocupaba a Freud (2013 [1930]). Entre el miedo a la pandemia se ha preferido en el mundo y el Perú la seguridad de la inmovilidad en el hogar. La vida cotidiana de las gentes muestra la cesión de una importante parte de la libertad a costa de un aumento en la seguridad del retiro doméstico. Esta libertad mutilada es el sacrificio del proceso de clausura y cuarentena para poder doblegar al Covid-19.

Sin embargo, la información disponible mostró que en marzo el 95\% la población apoyaba la seguridad del confinamiento, en mayo la aceptación era aprobada por una proporción del 36\% (Ipsos, 2020a y 2020b), claramente mostraba una tendencia relativamente decreciente (Pereda, 2020). ¿Qué ocurrió con el proceso de reclusión en el Hogar?, La expicación hipotética, en parte, tiene que ver con la informalidad de la población. Además, por otra parte, se relaciona con el carácter de la vida cotidiana teñida de violencia, generando una crisis en la seguridad del encierro. La pandemia ha desnudado la rudeza de nuestra vida cotidiana.

La mayor parte de las viviendas populares son reducidas, el baño se comparten por todos y carecen de los artefactos necesarios para recistir el encierro familiar, la información del 2017 evidencia un tercio de hogares sin refrigerador y el 61,6\% de las casa urbanas tenía entre tres y seis miembros, en muchos casos albergaban a más de un hogar. Asimismo, la vida en las viviendas reproducían momentos transitorios, por lo general para dormir, y luego para proseguir con la jornada de trabajo, ello fue interrumpido bruscamente, ahora con el Covid-19 se trata de reconvertirlos espacios definos de permanencia fija de los habitantes. 
Las diferencias entre hombre y mujer, muestran que son las mujeres las que llevan la peor parte de la crisis desatada por la enfermedad. La división del trabajo doméstico en la reclusión del hogar, por más colaboración del hombre, las principales tareas recaen en las mujeres. También en épocas del coranovirus el empleo se pierde, los hombres se sienten muy afectados y quizás lleven a desarrollar conductas violentas en el hogar. En efecto, pareciera que la agresión contra la mujer se incrementa. Entre el 16 de marzo y 19 de abril del período de la pandemia se registraron 3,060 casos de violencia familiar o sexual, 285 personas fueron detenidas por violación sexual y ocirrieron 6 feminicidios, sin tomar en cuenta las 14,000 denuncias recibidas y la situación de las 153 mujeres desaparecidas (Mannarelli et al., 2020). Cuadro social que expresaría aún el fundamento institucional de la dominación del patriarcado, carecterizado por facilitar el mayor poder del hombre sobre las mujeres, más allá de los avances de la cultura feminista en el país.

La diversidad de género/sexualidad, en sus grupos más vulnerables llevó al aumento de la discriminación y agresión. Las mujeres transgenero residentes en el Centro de Lima en minúsculos cuartos, con un gasto que se hace cada vez más imposible de pagar por la crisis de de la pandemia (Lira 2020). Las situaciones de mayor impacto, corresponde a la discriminación pública de mujeres trans en la comisaria de Bellavista y al peligro de hambre de más de 150 mujeres trans del Centro Histórico de la capital (Perú21, 2020). Proceso de discriminación y violencia que, de alguna forma, manifestaría la búsqueda de imponer valores uniformes patriarcales sobre la heterogeneidad de la sexualidad humana.

Los discapacitados, viejos y niños sometidos durante semanas al encierro en el hogar raya en una situación cercana al arresto domiciliario, han generado graves problemas de salud mental. Las personas se caracterizan porque siempre buscan la compañía directa, el abrazo, la reunión y la cercanía de los otros. No obstante que las relaciones interpersonales se han visto modificadas abruptamente, la prohibición de una socialización presencial es una forma violenta que deshumaniza. La relación entre las personas se han contraídos y distanciados, los individuos han tenido que reducirse a la familia durante el encierro, se alejaron de los parientes externos, vecinos, paisanos y amigos. Larga reclusión que vulnera la condición humana por medio de la coacción física en al vivienda y la pretención de alejarlo de los otros. Situación muy probable que pueda 
impulsar en las poblaciones un serio cuestionamiento a la pretendida seguridad de la población.

El el Perú la relación entre seguridad y libertad asume características particulares. Dicha relación pareciera no sede por la búsqueda de la libertad en la personas, que lo hay, principalmente se trastoca por la propia política de encierro en el hogar, de la seguridad, la vida cotidiana de la población lo ha desbordado y roto, transformando la inmovilidad en algo más informal, que real.

\section{A manera de conclusión: mercado, Estado y comunidad frente al Covid-19}

En tiempos de crisis abierto por la pandemia del Covid-19, el patron moderno digital se expande de modo creciente en el mundo y, a la vez, lo hace su lado oscuro, de la colonialidad, como la desigualdad social, la destrucción de la naturaleza, los oligopolios, las formas de autocontrol y la imposición de un proyecto de "barbarie cultural".

En esas condiciones, cobra especial importancia el mercado, el Estado y la comunidad como las dimensiones reguladorea de la vida social, en épocas de crisis de la actual pandemia, estos elementos se tornan centrales en la sociedad. Las políticas públicas, en gran parte, giran privilegiando algunos de estos factores o combinándolos, según la situación de los países.

El orden del mercado ha fracazado en toda sus potencialidades, ha sido la víctima inmediata de la pandemia. Las actuaciones neoliberales vergonsozas de Estados Unidos y Brasil muestran los casos extremos en el mundo de la expansión del Covid-19. Estados Unidos la nación más rica de la Tierra se muestra incapaz de accionar frente el Covid-19, allí cohabitan la mayor medicina del mundo y una lamentable salud para la población pobre. En Brasil ha primado el dejar hacer y dejar pasar del mercado con todas las consecuencias graves que ha padecido sus habitantes, el Presidente Bolsonaro lo llamo "pequeña gripe" sin Importanacia para preocuparse en definr una acción estatal (Paton, 2020).

La actuación del Estado presenta los mayorse éxitos en el enfrentamiento de la pandemia, el caso más importante es China por haber detenido los efectos del Covid-19, 
de alguna forma contando con el apoyo de la población. Sin ambargo, China ha recurrido principalmente a formas no-democráticas, despóticas del gobierno, las políticas públicas deliberadas han seguido el control y vigilancia tecnológica de las personas por medio de celulares y otros dispositivos informáticos, poniendo en peligro aún más la propia existencia de la libertad personal y la democracia.

La comunidad es la otra dimensión siempre presente, aunque invisibilizada oficialmente y no tomada en cuenta en las políticas públicas. La pandemia del Covid-19 además de la crisis de salud pública global, constituye una crisis comunitaria. Para enfrentar la enfermedad demanda de mucha solidaridad entre las personas, que únicamente lo puede ofrecer los niveles de institucionales de la comunidad, coresponde a lo que se denomina la sociedad civil. En el Perú las comunidades son las rondas urbanas, rondas campesinas, asociaciones de pobladores y la diversidad organizacional de barrios y pueblos, representan las agrupaciones "voluntarias" caracterizadas porque los de afuera no pueden entrar facilmente y los de dentro pueden salir libremente (Bauman, 2006, p. 114). En muchos casos controlan a la población afectada por la pandemia, sin anular la prerrogativa voluntaria para salir a trabajar y, a veces, recurren a la vigilancia de las personas afectadas por el Covid-19. El reto consiste en descubrir formas de colaboración que solo las comunidades lo pueden ofrecer, en momentos de crisis de la pandemia.

Experiencias de la vida social afectada por la pandemia grafican que solo tiene posibilidad el desarrollo de una lógica que vaya más allá del mercado. El miedo a la enfermedad tiene que vencer al individualismo del mercado, hay necesidad de recuperar la energía colectiva que produce el afecto, la confianza de la compañía duradera con los otros y la fortaleza de la comunidad. Punto inicial que posibilite situar en el centro de la sociedad la vida digna de las personas. Garantizando que los derechos fundamentales son la condición propia de ser humanos.

Finalmente, es fundamental subrayar que el Perú no ha llegado a situaciones extremas y catastróficas de la pandemia, como EE. UU., Italia, Brasil y México, pese a la crisis de la seguridad/encierro de la población. Pareciera aquí, que el papel activo e invisibilizado le corresponde fundamentalmente a la comunidad, en la que destaca el factor central de la colaboración y solidaridad entre las personas. 


\section{Bibliografía}

ADAMS, N. Y VALDIVIA, N. (1991). Los otros empresarios. Ética de migrantes y formación de empresas en Lima. IEP: Lima.

BANCO MUNDIAL (2020). Pobreza (I). Panorama General, 16 de abril. https://www.bancomundial.org/es/topic/poverty/overview

BAUMAN, Z. (2013). La cultura en el mundo de la modernidad Líquida. FCE: México

BAUMAN, Z. (2007). Libertad. Losada: Buenos Aires.

BAUMAN, Z. (2006). Comunidad. Siglo XXI: Madrid.

BAUMAN, Z. y DESSAL, G. (2014). El retorno del pédulo. Sobre psicoanálisis y el futuro del mundo líquido. FCE: Buenos Aires.

BROOKS, D. (2020): “Cuarentena en EU: 600 millonarios más ricos y 38 millones sin empleo". La Jornada, 25 de mayo. México.

https://www.jornada.com.mx/2020/05/25/mundo

CALDERÓN, F. y CASTELLS, M. (2019). La nueva América Latina. México: FCE.

CASTELLS, M. (2020). "Entrevista Wyoming a Manuel Castells. Censurar redes sociales". \#Enelojodelcuervo por Javier, 14 de mayo.

https://www.youtube.com/watch?v=1h1TelRGrP8

CASTELLS, M. (2019). “Seminário Comunicação, Política e Democracia”. FGV, 16 de julio: Río de Janeiro. https://www.youtube.com/watch?v=I4cizUYfZ18

CASTELLS, M. (1997). La era de la información. Economía, sociedad y cultura. Vol. 2. México: Alianza.

CEBALLOS, G.; EHRLICH, P.R.; BARNOSKY, A.; PRINGLE, R.M. y PALMER, T. M. (2015).

"Accelerated modern human-induced species losses: Entering the sixth mass extinction". Science Advances, Vol. 1, № 5,

http://advances.sciencemag.org/content/advances/1/5/e1400253.full.pdf

CEPAL (2020). "El desafío social en tiempos del COVID-19". Informe Especial COVID-19, №3, mayo.

https://repositorio.cepal.org/bitstream/handle/11362/45527/5/S2000325 es.pdf

ELCACHO, J. (2020). “Autralia en llamas. Más de 1.000 millones de animales muertos: escalofriante balance de los incendios". La Vanguardia, 9 de enero. Barcelona. https://www.lavanguardia.com/natural/20200109/472793016199/mas-de-1000-millonesde-animales-muertos-escalofriante-balance-de-los-incendios.html

EFE (2020). “Coronavirus Perú.COVID-19 causa cientos de muertes de médicos, policías y periodistas en Perú". Agencia EFE, 20 mayo. Lima. 
https://www.efe.com/efe/america/sociedad/covid-19-causa-cientos-de-muertesmedicos-policias-y-periodistas-en-peru/20000013-4251479

FANON, F. (2001). Los condenados de la Tierra. FCE: México.

FRANCKE, P. (2020). "Vigencia dramática: apuntalar la agricultura”. Hildebrant en su trece, № 490, 22 de mayo. Lima.

FREUD, S. (2013 [1930]). El malestar en la cultura. Madrid: Alianza.

FREIER, L. y GUSTAV BRAUCKMEYER, G. (2020). “Migrantes venezolanos y covid-19: impacto de la cuarentena y propuestas para la apertura". Burga, M.; Portocarrero, F. y Panfichi, A. (coordinadores): Por una nueva convivencia. La sociedad peruana en tiempos del COVID-19: escenarios, propuestas de política y acción pública". MINSA - PUCP: Lima.

GESTIÓN (2020). “Mininter: 82 policías han fallecido y más de 4,000 están contagiados con COVID-19", 14 de mayo. Lima. https://gestion.pe/peru/coronavirus-peru-ministrodel-interior-informa-que-82-policias-han-muerto-y-mas-de-4-mil-estan-contagiadoscon-covid-19-cuarentena-estado-de-emergencia-nndc-noticia/

HARARI, Y. (2020). “El mundo después del coronavirus”. La Vanguardia, 5 de abril. Barcelona.

https://www.lavanguardia.com/internacional/20200405/48285133216/yuval-hararimundo-despues-coronavirus.html

HOPKINS, J. (2020). "Centro de Recursos: Covid-19: Experiencias e información básica”, 8 de junio. University \& Medicine. https://coronavirus.jhu.edu/map.html

INEI (2020). Informe Ténico. Situación del mercado laboral en Lima Metropolitana. Trimestre móvil. 5 de mayo https://www.inei.gob.pe/media/MenuRecursivo/boletines/05-informe-tecnicon05 mercado-laboral-feb-mar-abr.2020.pdf

IPBES (2019). Comunicado de prensa: El peligroso declive de la naturaleza "sin precedentes": Tasas de extinción de especies 'aceleradas'. ONU. https://ipbes.net/news/Media-Release-Global-Assessment

IPSOS (2020a). Informe de Resultados. El COVID-19, marzo. Perú. https://www.ipsos.com/sites/default/files/ct/news/documents/202003/encuesta de opinion- cuarentena covid-19.pdf

IPSOS (2020b). Informe de Resultados. El COVID-19, mayo. Perú. https://www.ipsos.com/sites/default/files/ct/news/documents/202005/encuesta_nacional_urbana_mayo_2020_-el_covid_19_0.pdf

LA VANGUARDIA (2020). "Iglesias de Nueva York harán test de Covid-19 a negros y latinos en los barrios más castigados", 9 de mayo. Barcelona. https://www.lavanguardia.com/internacional/20200509/481049348497/test-covid-19iglesias-nueva-york-negros-latinos.html 
LAVELOCK, J. (2007). La venganza de la Tierra. La teoría de la gaia y el futuro de la humanidad. Barcelona: Planeta.

LIRA. A. (2020). "La lucha de las mujeres trans en tiempos de pandemia. Para la población estigmatizada, la emergencia nacional ha traído hambre y discriminación". El Comercio, Especiales: Lima. https://especiales.elcomercio.pe/?q=especiales/mujerestrans-en-tiempos-de-pandemia-ecpm/index.html

MANNARELLI, M.E.; MOTTA, A.; CARMEN YON, C.; L. ERIKA FIGUEROA, E. y SOTO, K. (2020). "Mujeres, género y pandemia en el perú". Burga, M.; Portocarrero, F. y Panfichi, A. (coordinadores): Por una nueva convivencia. La sociedad peruana en tiempos del COVID-19: escenarios, propuestas de política y acción pública”. MINSA - PUCP: Lima.

MEJÍA, J. (2016). “Cultura y dignidad en América Latina. Descolonialidad de la desigualdad social”. Investigaciones Sociales, № 37, pp. 315-324. Lima: UNMSM.

MONTOYA, R. (2020). "Quédese en casa', mano dura y democracia”. LAMULA.PE, 14 de mayo. Lima. https://rodrigomontoya.lamula.pe/2020/05/14/quedese-en-casa-manodura-y-democracia/rodrigomontoyar/

OIT (2020a). "El COVID-19 y el mundo del trabajo. Estimaciones actualizadas y análisis". Observatorio de la OIT. Segunda edición, 7 de abril de 2020.

https://www.ilo.org/wcmsp5/groups/public/---dgreports/--dcomm/documents/briefingnote/wcms 740981.pdf

OIT (2020b). "El COVID-19 y el mundo del trabajo. Estimaciones actualizadas y análisis". Observatorio de la OIT. Tercera edición, 29 de abril de 2020.

https://www.ilo.org/wcmsp5/groups/public/---dgreports/--dcomm/documents/briefingnote/wcms 743154.pdf

PATON, N.; SHELLEY, J.; DUWE, E. Y BONNETT, W. (2020). "Bolsonaro llama al coronavirus una "pequeña gripe". Dentro de los hospitales de Brasil, los médicos conocen la horrible realidad". CNN, 25 de mayo.

https://cnnespanol.cnn.com/2020/05/25/bolsonaro-llama-al-coronavirus-unapequena-gripe-dentro-de-los-hospitales-de-brasil-los-medicos-conocen-la-horriblerealidad/

PEREDA, D. (2020). “Encuesta telefónica del IEP. La frustración crece y pasa la factura a Vizcarra”. La República, 31 de mayo, pp.2-3. Lima.

PEÑARANDA, C. (2019). "La clase vulnerable alcanza al 34\% de la población peruana”. Informe Económico. Camára de Comerciode Lima - IEDEP. https://www.camaralima.org.pe/repositorioaps/0/0/par/r786_1/iedep_786.pdf

PÉREZ GUADALUPE, J. (2020). “Población penitenciaria: los transgresores”. Manuel Burga, M.; Felipe Portocarrero, F. y Panfichi, A. (coordinadores): Por una nueva convivencia. La sociedad peruana en tiempos del COVID-19: escenarios, propuestas de política y acción pública". MINSA - PUCP: Lima. 
PERÚ21 (2020). "Hambre durante el encierro: el drama de las chicas trans del Centro de Lima". 11 de abril: Lima. https://peru21.pe/lima/coronavirus-en-peru-hambredurante-el-encierro-el-drama-de-las-chicas-trans-del-centro-de-lima-pandemia-covid19-lgtbi-noticia/

QUIJANO, A. (ed.) (2014). Des/colonialidad y bien vivir. Un nuevo debate en América Latina. Lima: URP.

RAMONET, I. (2020). "La pandemia y el sistema-undo". La jornada,25 de abril. México. https://www.jornada.com.mx/ultimas/mundo/2020/04/25/ante-lo-desconocido-lapandemia-y-el-sistema-mundo-7878.html

SALAS, J. (2020). "La pandemia golpea más a los que menos tienen”. El País, 16 de mayo. Madrid. https://elpais.com/ciencia/2020-05-16/la-pandemia-golpea-a-los-que-menostienen.html

SEMINARIO, B: (2020). "Si las cosas siguen como están, sino se reactiva, Lima es inviable”. Gestión, 12 de mayo. Lima. https://gestion.pe/economia/bruno-seminario-silas-cosas-siguen-como-estan-si-no-se-reactiva-lima-es-inviable-noticia/

STANDING (2016). El precariado una nueva clase social. Barcelona: Pasado y Presente.

SUÁREZ, L.; ASUNCIÓN, M.; RIVERA, L. Y OTROS. (2020). Pérdida de naturaleza y pandemias. Un planeta sano por la salud de la humanidad. Madrid: WWF España.

ZIBECHI, R. (2020): “La idiotez de la vida urbana”. La Jornada, 8 de mayo. México. https://www.jornada.com.mx/2020/05/08/opinion/017a2pol 